\title{
Passenger Vehicle Emissions in Indonesia: Future Projections
}

\author{
Abdi Pratama ${ }^{1} \&$ Akihiro Tokai ${ }^{1}$ \\ ${ }^{1}$ Division of Sustainable Energy and Environmental Engineering, Graduate School of Engineering, Osaka \\ University, Osaka, Japan \\ Correspondence: Abdi Pratama, Division of Sustainable Energy and Environmental Engineering, Graduate \\ School of Engineering, Osaka University, S4 Building, 2-1 Yamadaoka, Suita, Osaka 565-0871, Japan. Tel: \\ 06-6879-7678. Email: abdi@em.see.eng.osaka-u.ac.jp
}

\author{
Received: July 3, $2018 \quad$ Accepted: August 17, $2018 \quad$ Online Published: November 29, 2018 \\ doi:10.5539/jsd.v11n6p222 URL: https://doi.org/10.5539/jsd.v11n6p222
}

\begin{abstract}
This study examines the effect of the low-cost green car (LCGC) policy that was introduced to control emissions from passenger vehicles in Indonesia. We examine the policy's effectiveness by estimating the level of emissions of $\mathrm{CO}, \mathrm{HC}, \mathrm{NO}, \mathrm{CO}_{2}$ under two scenarios: with and without LCGCs. The affordable price of LCGCs and the strict enforcement of the vehicle purchase system led us to estimate the growth in the number of vehicles using minimum annual income as a measure of people's ability to buy a new car. An annual income of US\$4,500$\$ 10,000$ was considered to represent the people who could buy an LCGC. Annual travel distance was obtained from a survey of drivers, and the deterioration factor from the Euro 2 standard was used. The results showed that the LCGC policy will potentially cause a significant increase in emissions of CO, HC, and NO by 2030 . The LCGC scenario predicted 1,389.7, 31.0, and 279.5 tons of CO, NO, and HC, respectively, compared with 670.3 , 15.1 , and 136.6 tons, respectively, for the scenario without LCGCs, an increase of $51.7 \%, 48 \%$, and $51.2 \%$, respectively. For amount of $\mathrm{CO}_{2}$, although LCGC policy could save more than 104,881 tons, the gap is increasing until end of projection in 2030, 3.3 times bigger between corresponding year, 49,411 tons and 14,892 tons for with and without LCGC policy, respectively.
\end{abstract}

Keywords: emissions, passenger car, low-cost green car, Indonesia

\section{Introduction}

In September 2013, the Indonesian government launched a new policy known as low-cost green car (LCGC) after a one-year delay. The LCGC policy introduced regulations requiring fuel consumption of $20 \mathrm{~km}$ per liter and an engine capacity of between 0.99 and 1.2 liters for gasoline-fueled cars and $1.5 \mathrm{~L}$ for diesel-fueled cars based on UN-R 101. The fuel specification is based on a Research Octane Number of 90 for gasoline and a Cetane Number of 51 for diesel with a maximum wheel handle turning radius of 4.6 meters. This turning radius reflects the size of the LCGCs, because cars usually have a turning radius of more than 4.7 meters (MOE 2003). The LCGCs are smaller than current multi-purpose vehicles (MPVs) or passenger sedans (with an engine capacity $>1.5$ liters) (Gaikindo 2015).

By way of compensation, all owners of vehicles fulfilling this requirement will receive an incentive in the form of a tax cut (MOI 2013). This regulation has been introduced in response to the decline in domestic oil reserves and the high level of consumption in the transportation sector. These concerns have been exacerbated by the growth in the number of passenger vehicles, with the total number tripling between 2001 and 2012 (Gaikindo 2015). Consequently, $\mathrm{CO}_{2}$ emissions from vehicles have also increased significantly. According to data provided by the CDIAC (2013), Indonesia was ranked 12th in the world in terms of $\mathrm{CO}_{2}$ emissions. One of Indonesia's main sources of $\mathrm{CO}_{2}$ emissions is the consumption of liquid petroleum products, which accounted for more than $36 \%$ of total emissions (CDIAC 2013).

From the economic efficiency point of view, a cost-benefit analysis (MOF 2013) outlined expectations as a result of the implementation of the LCGC policy. It was expected that the policy could attract US\$1.4 billion in new investment, increase tax revenue by US $\$ 26$ million, and provide new jobs for 315,835 people. The decrease in fuel consumption is also predicted to contribute to reductions in $\mathrm{CO}_{2}$ emissions. However, detailed calculations in relation to emissions were not provided.

Thus, the purpose of this study is to analyze the predicted effects of the LCGC policy by estimating changes in 
$\mathrm{CO}, \mathrm{HC}, \mathrm{NO}$, and $\mathrm{CO}_{2}$ emissions.

\section{Materials and Method}

\subsection{Research Framework}

The research framework contains three important elements. The LCGC ownership model shows how LCGCs will penetrate the current vehicle market. The LCGC policy regulation specifying a maximum car price leads to a specific segment of the population with an annual income that enables them to purchase an LCGC based on a constructed ownership model. The car population model estimates the changes in the numbers of various types of cars after the LCGC policy is implemented. Changes in emissions of $\mathrm{CO}, \mathrm{NO}, \mathrm{HC}$, and $\mathrm{CO}_{2}$ are derived using an emissions estimation model. These models use primary data from a survey of car owners, in particular annual travel distance and fuel consumption, and secondary data from government and association reports.

Cars are classified based on the emissions control standard, and are divided into two categories; Euro cars, which meet the Euro 2 emissions standard, and non-Euro cars. While we focus on Euro cars, non-Euro cars must be considered because of their emissions, current condition, and numbers remaining in the market, as there is no regulation limiting the life of vehicles in Indonesia. The number of non-Euro cars remained unchanged following the implementation of the Euro 2 emissions standard as part of the "Decree of The State Minister of Environment of Republic Indonesia No 141 Year 2003," which was enacted in 2003 and implemented from 2005 until 2007 (Nugroho and Fujiwara 2005). The numbers of non-Euro cars are shown in the results of our analysis to identify the proportion of these cars in the overall car population and their estimated effect on emissions levels.

In this research framework, we specify two scenarios: with LCGCs and without LCGCs. All vehicles satisfying the requirements of the LCGC policy are categorized as LCGCs, otherwise they are categorized as non-LCGCs. It was found that the LCGC category, which includes vehicles manufactured after 2013, is dominated by Euro cars, while the non-LCGC category, which includes vehicles manufactured prior to 2013, includes both Euro and non-Euro cars.

Sensitivity analysis was also conducted to validate the model. Several elements of the car ownership model are important determinants of future projections, and thus we compared emissions levels under various conditions to estimate the potential effects of the LCGC policy. The difference between the two scenarios was considered to represent the effectiveness of the LCGC policy from an environmental perspective, as it identified the levels of emissions from controlled gasoline-fueled passenger cars.

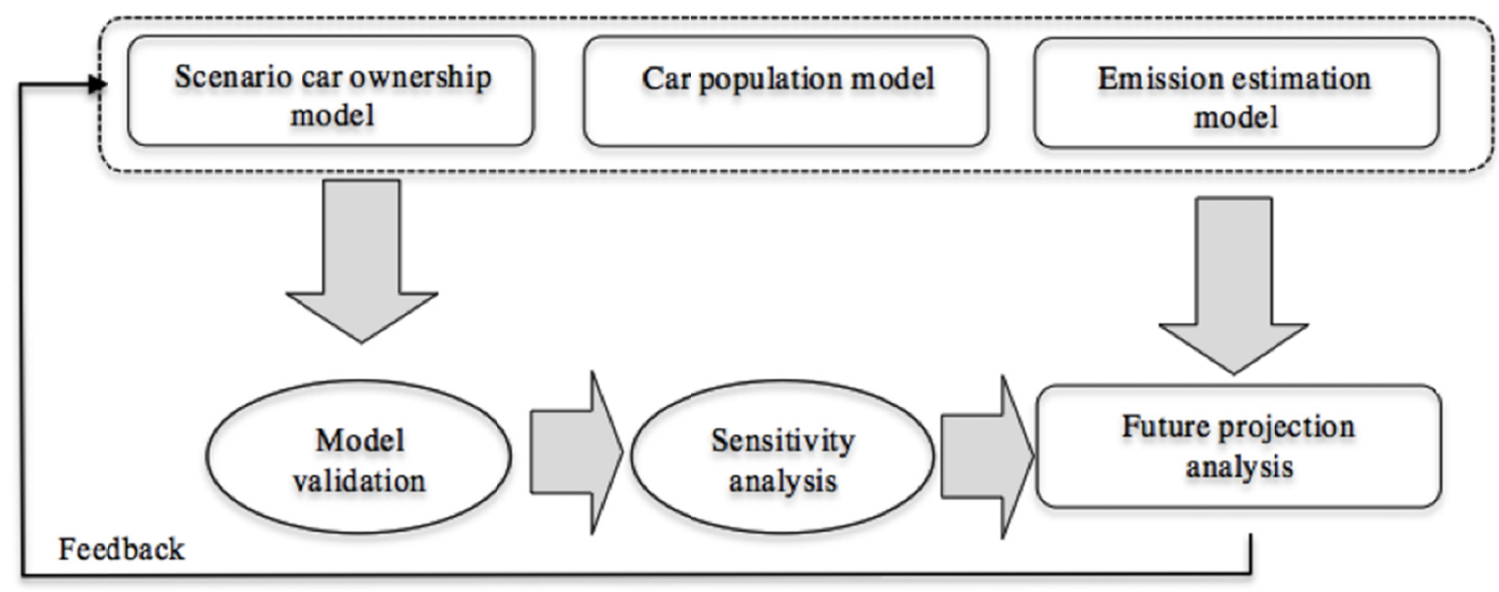

Figure 1. Research framework

This research framework is effective for the period since the LCGC policy was implemented in 2013. Figures relating to non-LCGCs prior to 2013 were obtained from government reports.

\subsection{Research Scope}

This study focuses on estimating the changes in vehicle emissions levels after the LCGC policy was implemented in Indonesia. The scope of the study is the total car population in Indonesia, and regional characteristics such as driving behavior, which might affect annual travel distance, are not considered. We took 
the average of annual travel distances from five different locations, ignoring regional variations. The driving environment, which includes road conditions such as road surface and gradient that might cause variations in the levels of emissions and fuel consumption, is also beyond the scope of this research. Measurements of the emissions and fuel consumption of individual cars, as well as the ambient air conditions are necessary, and the high number of cars means that these measurements are difficult and expensive to obtain.

\subsection{LCGC and non-LCGC Scenario Models}

We built two scenarios based on people's annual income: with LCGCs and without LCGCs, as shown in Table 1. We set the average LCGC price at US\$9,500 (MOI 2013), as regulated by the government, and the non-LCGC price at US\$20,000, which was the average list price of a Toyota MPV (TAM 2013), which accounts for more than $50 \%$ of vehicle sales in Indonesia (Gaikindo 2015).

Table 1. Scenarios with and without LCGCs

\begin{tabular}{lccc}
\hline Elements & $\begin{array}{c}\text { With LCGC } \\
\text { loan) }\end{array}$ & scenario (5 years & $\begin{array}{c}\text { Without } \\
\text { loan) }\end{array}$ \\
\hline Average price (USD) & 9,500 & & 20,000 \\
Downpayment (\%) & 30 & 30 \\
Downpayment amount (DP) (USD) & 2,850 & 6,000 \\
Annual interest rate (\%) & 12.42 & 12.42 \\
Duration (N) (Months) & 60 & 60 \\
Borrowing amount (BM) (USD) & 6,650 & 14,000 \\
Interest payment (I) (USD) & 826 & 1,739 \\
Monthly installment (M) (USD) & 125 & 262 \\
Monthly income eligible (USD) & 415 & 787 \\
Minimum annual income (AM) & 4,984 & 9,443 \\
(USD) & & & \\
\hline
\end{tabular}

In the LCGC scenario, the number of cars is determined by the number of people with a minimum annual income of US\$4,984. All people in this segment (>US\$4,984) will be deemed to select an LCGC car once the policy is implemented. Meanwhile, in the scenario without LCGCs, only people with a minimum annual income of US $\$ 9,443$ will have the option of purchasing a non-LCGC.

In these scenarios, people's minimum annual income was used to estimate the growth in the car population. Crossover purchases, double ups, and repeat buying are not included in this estimation, nor is driving behavior in relation to both vehicle types. Annual travel distance, which was obtained from the survey data, is applicable to both vehicle types. Considering those particular elements need further discussion in the next work.

Our estimates of growth in the car population after the implementation of the LCGC policy using an income-based approach was based on the study of (Sanjaya, Kevin Kynan, Diah Indriani 2014). We analyzed people's survey responses regarding the main reason for choosing an LCGC, and concluded that of the five options offered (financial benefit, environmental benefit, social and norm pressure, self-image, and interest in new technology), financial benefit is the main reason why people select an LCGC. Pongthanaisawan and Sorapipatana 2010 reported that in a developing country such as Thailand, with economic growth estimated to be 3.2 in 2016 and 3.5 in 2017 (ADB 2016), the number of private vehicles increases as people's income rises. Initially, motorcycles are the dominant form of transport; however, as soon as income reaches a certain level, consumers shift from motorcycles to cars because of their convenience, comfort, and safety. Indonesia, with estimated economic growth of 3.4 in 2016 and 3.5 in 2017, as reported by the Asian Development Bank (ADB), is expected to display a similar tendency (ADB 2016).

A down payment of $30 \%$ of the price of the car is required, as regulated by Bank of Indonesia (BI 2013) for individuals purchasing cars for private use. Prior to the enforcement of this policy, the amount required by way of a down payment was not strictly regulated, and the percentage was allowed to vary depending on the degree of trust on the part of the car dealer. Therefore, purchase capability was difficult to measure. An interest rate of 
$12.42 \%$, which can fluctuate monthly, was derived from the average annual interest rates of ten major banks in Indonesia (BI 2015). The advent of an economic crisis could render interest rates difficult to control; however, this possibility was excluded, because we consider such a crisis to be an irregular condition. We set the loan duration to a maximum of 60 months (five years) in accordance with the terms offered by four major banks according to their official websites (BCA 2016)(Mandiri 2016)(BRI 2016). A longer loan duration is considered to be the most desirable option for customers, as it enables them to spread their loan repayments, thereby reducing the financial impact. A down payment of $30 \%$ of the car's price means they are required to pay US $\$ 2,850$ for an LCGC and US $\$ 6,000$ for a non-LCGC, with interest payments (I) of US\$826 and US\$1,1739, respectively. The monthly installment is derived using equation (1):

$$
M=\frac{B M}{N}(1+I)
$$

where $M$ is the monthly installment (US\$), $N$ is the duration of the loan (months), $B M$ is the amount borrowed (US\$), and $I$ is the interest rate (\%). Minimum annual income is calculated using equation (2):

$$
A M=12 \cdot\left(\frac{M}{D P}\right)
$$

where $A M$ is the minimum annual income of the potential buyer (US\$) and $D P$ is the down payment required (\% of total price).

Therefore, the minimum annual income required to purchase either an LCGC or a non-LCGC will be US $\$ 4,984$ or US\$9,443, respectively, as shown in Table 1. To estimate the numbers of potential LCGC and non-LCGC buyers, we divide annual income data into the following segments: $<$ US $\$ 350$, US $\$ 350-\$ 550$, US\$550-\$800, US $\$ 800-\$ 1,100$, US $\$ 1,100-\$ 1,600$, US $\$ 1,600-\$ 2,500$, US $\$ 2,500-\$ 4,500$, US $\$ 4,500-\$ 10,000$, US $\$ 10,000$ $\$ 25,000$, and $>$ US $\$ 25,000$. The population in each income segment is shown in Appendix A (GIDD 2015).

It can be seen from Table 1 that both the $A M$ of US $\$ 4,984$ for buying an LCGC and that of US $\$ 9,443$ for buying a non-LCGC fall within the US\$4,500-\$10,000 segment. It will be taken from segment range annual income US\$10,000-\$25,000. The difference between the $A M(\mathrm{US} \$ 4,984)$ and the lower limit of the segment of US\$4,500 (9.7\%) will be considered on the estimating new buyer calculation. We approach number of LCGC and non-LCGC car with the number of population of range US\$4,500-\$10,000 and US\$10,000-\$25,000. Hence, these annual income segments are used to represent the potential numbers of buyers of LCGCs and non-LCGCs, respectively. Considering complex participation rate in actual market will be the next important topic to increase the accuracy completing this research.

\subsection{Car Population Model}

The car population model represents the stock of cars $(S C)$ after the implementation of the LCGC policy using the ownership model shown in Table 1. The total $S C$ includes LCGCs $(N A)$ and non-LCGCs $(N B)$. NB includes both Euro cars and non-Euro cars, while $N A$ only includes Euro cars following the enforcement of the emissions standard (Nugroho and Fujiwara 2005).

Considering that the LCGC policy is designed to boost economic growth through new investment (MOF 2013), the low-cost of vehicles (maximum US\$10,000) allows a new annual income segment to enter the market. We define the total $S C$ as the sum of the number of LCGCs and the number of non-LCGCs, as shown in equation (3):

$$
S C=N A+N B
$$

where $S C$ is the total stock of cars, $N A$ is the number of LCGCs, and $N B$ is the number of non-LCGCs.

For the period prior to the implementation of the LCGC policy in 2013, we used secondary data from the annual report provided by (Gaikindo 2015). However, after policy implementation, there are both $N A$ and $N B$ in the total $S C$. Hence, we use segmented annual data from (GIDD 2015) to estimate both values. A reduction in the number of cars as a result of a natural disaster is considered to be an irregular condition that would require more detailed investigation.

\subsection{Estimation Model for CO, HC, and NO Emissions}

To estimate projected emissions of $\mathrm{CO}, \mathrm{NO}, \mathrm{HC}$, and $\mathrm{CO}_{2}$, we use annual travel distance (ATD), annual fuel consumption $(A F C)$, an emissions factor $(E F)$, and a deterioration factor $(D F)$. Equation (4) is used to calculate $\mathrm{CO}$, $\mathrm{NO}$, and $\mathrm{HC}$ emissions, while $\mathrm{CO}_{2}$ emissions are calculated using equation (8). 


\subsubsection{Emissions Calculations}

Total emissions $(E)$ are calculated using equation (4). This equation has been used in previous studies such as (Hong Huo 2011) when modeling vehicle emissions in various cities in China:

$$
\begin{aligned}
& E=A T D \cdot E F \cdot D F \cdot S C \\
= & \left(\frac{1}{n} \sum_{i=1}^{n} x_{i}\right) \cdot E F \cdot D F \cdot(N A+N B)
\end{aligned}
$$

where $E$ is total emissions of CO, HC, and NO (tons) after LCGC policy implementation, ATD is the annual travel distance $(\mathrm{km}), E F$ is the emissions factor $(\mathrm{g} / \mathrm{km}), D F$ is the deterioration factor $(60 \%$ after $80,000 \mathrm{~km}$; CO, $3.52 \mathrm{~g} / \mathrm{km} ; \mathrm{HC}, 0.08 \mathrm{~g} / \mathrm{km}$; NO, $0.72 \mathrm{~g} / \mathrm{km}), S C$ is the total stock of cars, $n$ is the number of respondents, $x_{i}$ is each respondent's odometer reading $(\mathrm{km}), N A$ is the number of LCGCs, and $N B$ is the number of non-LCGCs. The values of $A T D$ and $S C$ are much higher than those of $E F$ and $D F$, and thus have a significant impact on $E$, although improvements in $E F$ and $D F$ will also help to control $E$. The inclusion of $D F$ increases the accuracy of changes in the level of emissions because of the deterioration of catalytic converters over time.

\subsubsection{Annual Travel Distance (ATD)}

To estimate the $A T D$, we conducted a survey of 120 people who own and drive a car in one of Indonesia's three biggest cities, Jakarta, Surabaya, and Medan, which account for. more than $32.9 \%$ of all passenger vehicles in Indonesia (BPS 2013). The respondents completed the questionnaire during an interview, and were required to answer all questions, which were constructed to ensure that they could be answered legitimately. We also questioned respondents about their driving behavior such as their driving style during passing asphalt road and loading behavior.

$A T D$ was calculated as the average of all respondents' odometer readings. The odometer reading method is one way of estimating distance travelled (Hossain and Gargett 2011), while another way involves calculations based on fuel purchases. ATD is the sum of each respondent's odometer reading divided by the total number of respondents' odometer readings $\left(\mathrm{x}_{\mathrm{i}}\right)$, as shown in equation (5):

$$
A T D=\frac{1}{n} \sum_{i=1}^{n} x_{i}
$$

where ATD is the annual travel distance $(\mathrm{km}), n$ is the number of respondents, and $x_{i}$ is each respondent's odometer reading $(\mathrm{km})$. To avoid misreadings, we ensured that each respondent was able to confirm that their odometer had not been replaced as a result of an accident or damage incurred in other ways.

The survey of 120 respondents from three large cities is assumed to provide representative values for the purposes of this study. However, factors such as infrastructure capacity, driving behavior, and actual odometer measurements should be examined in future studies using a larger sample size.

\subsubsection{Emissions Factor $(E F)$ and Deterioration Factor $(D F)$}

The determination of the $E F$ considers the degradation of the catalytic converter that is installed to control emissions from internal combustion engines. This degradation occurs as a result of a decline in the catalytic converter's conversion capacity. This can be caused by fuel quality, combustion conditions, and aging. Table 2 shows that the emissions standards for $\mathrm{CO}, \mathrm{NO}$, and $\mathrm{HC}$ are $2.2,0.05$, and $0.45 \mathrm{~g} / \mathrm{km}$, respectively (Nugroho and Fujiwara 2005).

The $D F$ of $60 \%$ reflects the findings of a study indicating that emissions of $\mathrm{CO}$, NO, and $\mathrm{HC}$ increase by $60 \%$ from initial levels after the vehicle has travelled $80,000 \mathrm{~km}$ (Boulter 2009). This increase is also caused by deterioration of the catalytic converter, which cannot be neglected (Borken-Kleefeld and Chen 2015), and therefore should be included in calculations. Driving behavior and vehicle maintenance are other important factors that can affect this degradation. However, in this study, we do not include these factors in our calculations.

Since there is no regulation restricting the age of vehicles, the life of the vehicle is not considered. Indonesia is yet to introduce either a retirement program for old cars or a replacement program for newer cars, as has been done in several countries such as France (Yamamoto, Madre, and Kitamura 2004), Germany (Böckers, Heimeshoff, and Müller 2012), and Ireland (Hennessy and Richard 2011). However, old non-Euro cars are not included in this study. 
Table 2. Emissions standard and deterioration factor for Euro 2 vehicles

\begin{tabular}{|c|c|c|c|c|c|c|c|}
\hline \multirow{2}{*}{ Vchicle type } & \multirow{2}{*}{$\begin{array}{l}\text { Fuel Consumption } \\
\qquad(\mathrm{km} / \mathrm{L})\end{array}$} & \multirow{2}{*}{$\begin{array}{l}\text { Emission } \\
\text { Standard }\end{array}$} & \multirow{2}{*}{ Condition } & \multicolumn{3}{|c|}{ Amount of gas emission } & \multirow{2}{*}{ Deterioration factor } \\
\hline & & & & $\mathrm{CO}(\mathrm{gr} / \mathrm{km})$ & $\mathrm{NO}(\mathrm{gr} / \mathrm{km})$ & $\mathrm{HC}(\mathrm{gr} / \mathrm{km})$ & \\
\hline LCGC car & 20 & \multirow[b]{2}{*}{ Euro 2} & Initial value & 2.2 & 0.05 & 0.45 & \multirow{2}{*}{$\begin{array}{c}60 \% \text { increase after } \\
80,000 \mathrm{~km}\end{array}$} \\
\hline $\begin{array}{l}\text { Non-LCGC } \\
\text { car }\end{array}$ & 9.8 & & $\begin{array}{c}\text { After } 80,000 \\
\text { kilometer travelled }\end{array}$ & 3.52 & 0.08 & 0.72 & \\
\hline
\end{tabular}

\subsection{Emissions Estimation Model for $\mathrm{CO}_{2}$}

$\mathrm{CO}_{2}$ is created from the combustion of fossil fuels. The United States Environmental Protection Agency (EPA) has reported that typically, more than $99 \%$ of the carbon in the fuel will be emitted as $\mathrm{CO}_{2}$, while very small amounts of $\mathrm{HC}$ and $\mathrm{CO}$ are also emitted, these being converted to $\mathrm{CO}_{2}$ in the atmosphere (EPA 2014). The EPA uses an $E F$ of $2.348 \mathrm{~g}$ of carbon per liter of gasoline (EPA 2014). To calculate the amount of $\mathrm{CO}_{2}$ emitted, it is necessary to know the amount of fuel that is consumed.

\subsubsection{Annual Fuel Consumption $(A F C)$}

$A F C$ for LCGCs $(F C A)$ and non-LCGCs $(F C B)$ was obtained from respondents' fuel usage records provided in response to a survey question. Average $F C B$ was calculated based on respondents' $A F C\left(y_{i}\right)$. Since there was no regulation controlling the minimum fuel consumption, $F C B$ cannot be standardized to that of an LCGC, with minimum fuel consumption of $20 \mathrm{~km} / \mathrm{L}$. Hence, dividing $A T D$ by 20 provides an estimate of $A F C$ by LCGCs $(F C A)$, as shown in equation (6), while the calculation of FCB is given by equation (7):

$$
\begin{gathered}
F C A=\frac{A T D}{20} \\
F C B=\frac{1}{n} \sum_{i=1}^{n} y_{i}
\end{gathered}
$$

where $F C A$ is the $A F C$ for LCGCs (L), $F C B$ is the $A F C$ for non-LCGCs (L), $n$ is the number of respondents, $y_{i}$ is each respondent's $A F C$ (L), GCA is the amount of carbon emitted by LCGCs, and $G C B$ is the amount of carbon emitted by non-LCGCs. $A F C$ for non-LCGCs is estimated based on the average fuel usage reported by respondents during the survey (see equation (3)).

$$
\begin{gathered}
G C=G C A+G C B \\
G C=[(F C A \cdot N A)+(F C B \cdot N B)] \cdot M D \\
=\left[\left(\frac{A T D}{20}\right) \cdot N A+\left(\frac{1}{n} \sum_{i=1}^{n} y_{i}\right) \cdot N B\right] \cdot M D
\end{gathered}
$$

where $G C$ is the amount of $\mathrm{CO}_{2}$ (tons), GCA is the amount of $\mathrm{CO}_{2}$ from LCGCs (tons), GCB is the amount of $\mathrm{CO}_{2}$ from non-LCGCs (tons), $N A$ is the number of LCGCs, $N B$ is the number of non-LCGCs, FCA is the $A F C$ for LCGCs (L), FCB is the $A F C$ for non-LCGCs (L), and $M D$ is the density of gasoline $\left(\mathrm{kg} / \mathrm{m}^{3}\right)$.

Because LCGCs are required to comply with the specification of $20 \mathrm{~km} / \mathrm{L}$, as shown in equation (6), we use this figure for our calculations. Although the LCGC standard for minimum fuel consumption is following the designated driving pattern, we consider it is not significantly affect to the actual fuel consumption, since that driving pattern is reflected from the actual driving pattern that be standardized.

\subsection{Sensitivity Analysis}

We conducted a sensitivity analysis to determine the most significant factors affecting the estimation results. We selected three elements, namely, average car price, amount of down payment, and duration of loan. Adjusting those elements produced either positive or negative responses in relation to projected emissions. A reduction in emissions is considered a positive response, while an increase in emissions is considered a negative response. In relation to the average car price and down payment, we set sensitivity to $\pm 10 \%$ of the initial average price and down payment, while loan duration was set to between three and eight years. Adjusting the values of these elements affected the estimated amounts of $\mathrm{CO}, \mathrm{NO}, \mathrm{HC}$, and $\mathrm{CO}_{2}$ emissions. 


\section{Results and Discussion}

\subsection{Estimation of the Stock of Cars (SC)}

Here, we estimate the change in $S C$ following the implementation of the LCGC policy. We compare the scenarios with and without the LCGC policy by utilizing the annual income segment of US $\$ 4,500-\$ 10,000$ (see Appendix A), approached and fitted with regression analysis. The fitted regression line is determined by the value of the coefficient of determination, which varies between 0 and 1 . A higher value indicates a better accommodation of the data distribution. The value nearly 1 is considered generated equation is properly expressed the actual distribution.

The SC shown in Figure 2 consists of both $N A$ and $N B$. In the period before the LCGC policy was introduced, the $S C$ showed an average annual growth rate of 3\%. Car purchases were not well controlled, either in terms of financial schemes or ownership restrictions, nor was the minimum down payment strictly regulated. This meant that the down payment could vary, and did not necessarily reflect the ability of the buyer to purchase a new car. Car loans were based on trust between the car dealer, the leasing company, and the prospective buyer.

Figure 2 shows the situation before and after the LCGC policy was implemented. The pre-LCGC data shows the similar trend to scenario with LCGC and without LCGC estimation until policy implemented in 2013. The numbers of non-LCGCs are also plotted.

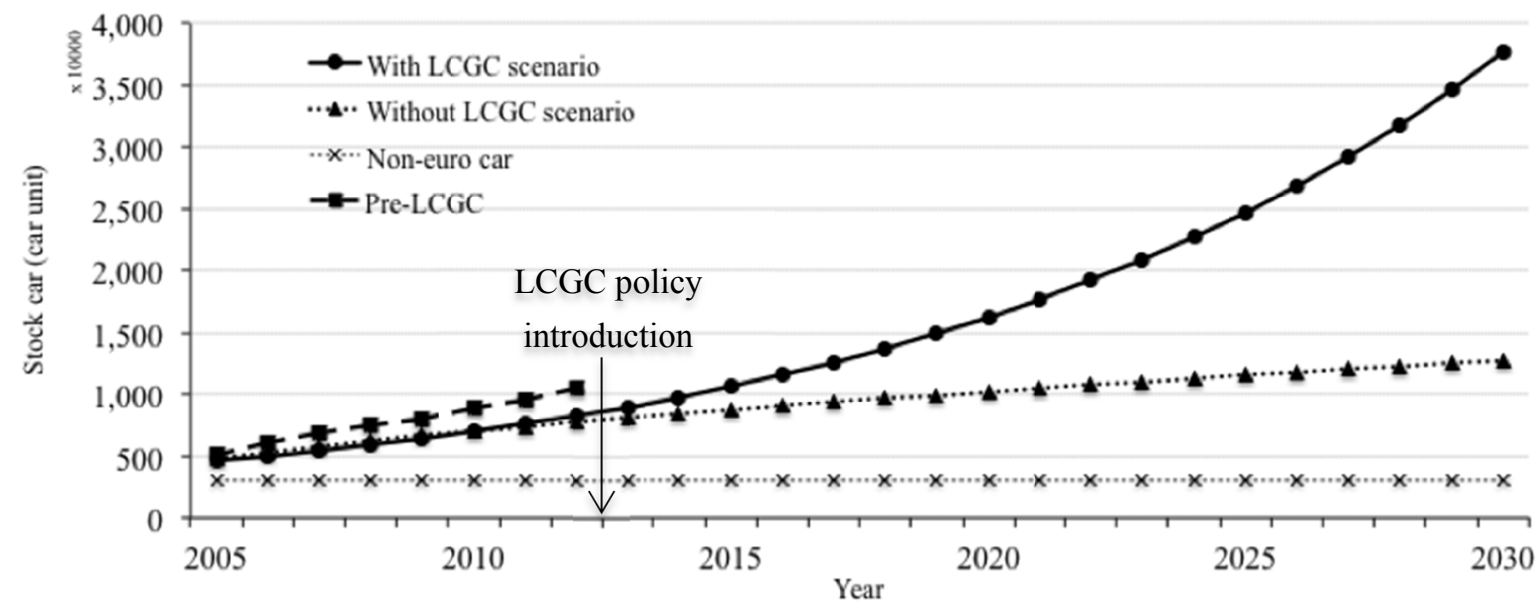

Figure 2. Growth in the stock of cars with and without the LCGC policy

The data shown in Table 1 were used to estimate the trends in the $S C$ with and without the LCGC policy. After dispersing in 2013, scenario with LCGC is growing up significantly because people with an annual income of $\$ 4,500-\$ 10,000$ (see Appendix A), who were not previously able to purchase a new car, were able to enter the market as new car buyers. Although there was stricter enforcement of down payment requirements, this did not significantly hinder the growth in the number of new car buyers in this income segment. Figure 2 shows that the introduction of the LCGC policy provided a boost to the car market, prompting strong growth in sales of new vehicles. Price remained the most important factor influencing people's decision to purchase a new car.

Following the implementation of the LCGC policy, the $S C$ has gradually increased since 2014, and this is projected to continue until 2023. By 2030, the number of passenger vehicles is expected to be double what it would have been without the introduction of the LCGC policy. Without the introduction of LCGCs, the $S C$ is limited to non-LCGCs, which are more expensive, and thus require purchasers to have a higher minimum annual income to fulfill the car ownership scenario outlined in Table 1. Furthermore, by 2030, the total number of cars will reach approximately 35 million, which is three times greater than the estimated number of cars without the introduction of the LCGC policy. The difference between the scenarios with and without the LCGC policy is the result of the inclusion of new buyers with annual incomes in the range US\$4,500-\$10,000. Thus, the minimum annual income is a significant factor.

\subsection{Estimation of the Effect of the Deterioration Factor (DF)}

The emissions of $\mathrm{CO}, \mathrm{HC}$, and $\mathrm{NO}$ for an individual car were calculated using equation (4) to take into account $A T D, E F$, and $D F$ shown in Table 2. $A T D$, which was calculated using data from the survey as per equation (5), 
was $13,000 \mathrm{~km}$ per year. The purpose of the travel varied, and included commuting from home to the office, business, or leisure pursuits.

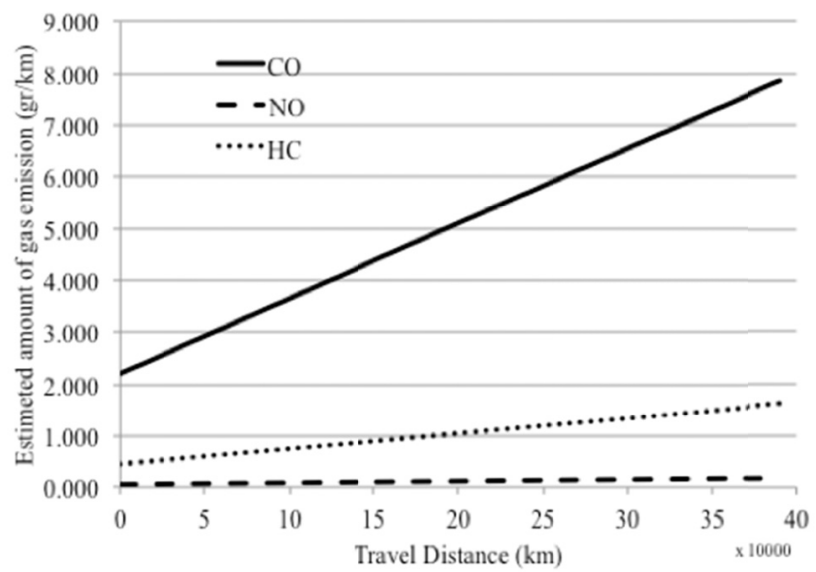

Figure 3. Effects of the deterioration factor on emissions of $\mathrm{CO}$, NO, and $\mathrm{HC}$

The effects of the deterioration of the catalytic converter are shown in Figure 3. Table 1 shows that emissions will be $60 \%$ higher after $80,000 \mathrm{~km}$ of travel, which corresponds to a car age of seven years, as the ATD was calculated as 13,000 km. The Euro 2 emissions standard specifies levels of 0.05 and $0.45 \mathrm{~g} / \mathrm{km}$ for NO and HC respectively, while $\mathrm{CO}$ is at the much higher level of $2.2 \mathrm{~g} / \mathrm{km}$. Emissions increase as the vehicle travel distance increases. Increasing travel distance also reflects increasing car age. Given that emissions increase by $60 \%$ after $80,000 \mathrm{~km}$, the new levels for CO are 3.52, 4.84, and $6.16 \mathrm{~g} / \mathrm{km}$ after $80,00,160,000$, and 240,000 km, respectively. These travel distances correspond to car ages of seven, 14, and 21 years, respectively. Since there is no limit to car life, these emissions levels will increase indefinitely.

\subsection{Estimation of CO, NO, and HC Emissions, Validation, and Future Projections}

Figure 4 shows that emissions of $\mathrm{CO}, \mathrm{NO}$, and $\mathrm{HC}$ in the LCGC scenario are higher than those in the scenario without LCGCs. Pre-LCGC data are also presented to validate the approach used. All pre-LCGC emissions of $\mathrm{CO}, \mathrm{NO}$, and $\mathrm{HC}$ are similar to the estimated figures, with non-LCGCs contributing significant amounts of emissions.

Emissions of CO (Figure 4a), NO (Figure 4b), and HC (Figure 4c) will be 1.3 times greater by 2020 under the LCGC policy than they would be if the LCGC policy was not implemented. The gap between these scenarios also increases significantly during the 10 -year period following implementation. Further, $\mathrm{NO}$ and $\mathrm{HC}$ emissions will be $34 \%$ and $39 \%$ higher, respectively, by 2020 than they were in 2015. Surprisingly, CO emissions will also increase, from 306.8 tons in 2014 to 434.1 tons in 2020 . This differs significantly from the estimated increase without policy implementation. The gap between emissions with and without the LCGC policy is also increasing because the rising number of cars is producing more emissions.

By 2030, the LCGC scenario will result in significant increases in emissions compared with the scenario without LCGCs. Emissions of CO, NO, and HC under the LCGC scenario will be 1,389.7, 31.0, and 279.5 tons, respectively, compared with $670.3,15.1$, and 136.6 tons, respectively, under the scenario without LCGCs, an increase of $51.7 \%, 48 \%$, and $51.2 \%$, respectively. Although the market share of LCGCs will increase significantly, the increase in emissions is a consequence of the implementation of the LCGC policy, something that has probably not previously been considered. The fact that an increasing level of car ownership is seen as a positive economic trend is likely the main reason for the implementation of the LCGC policy. 
(a)

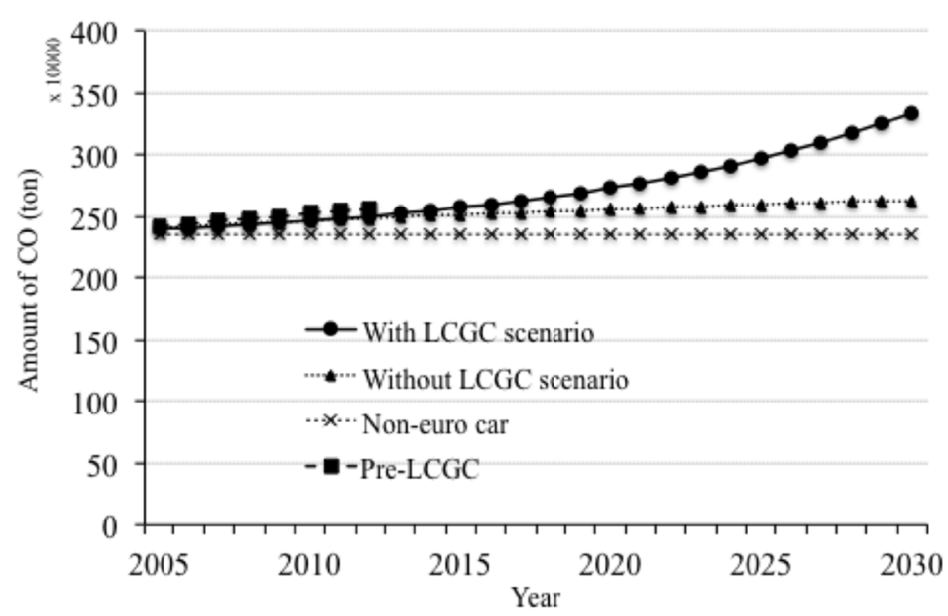

(b)

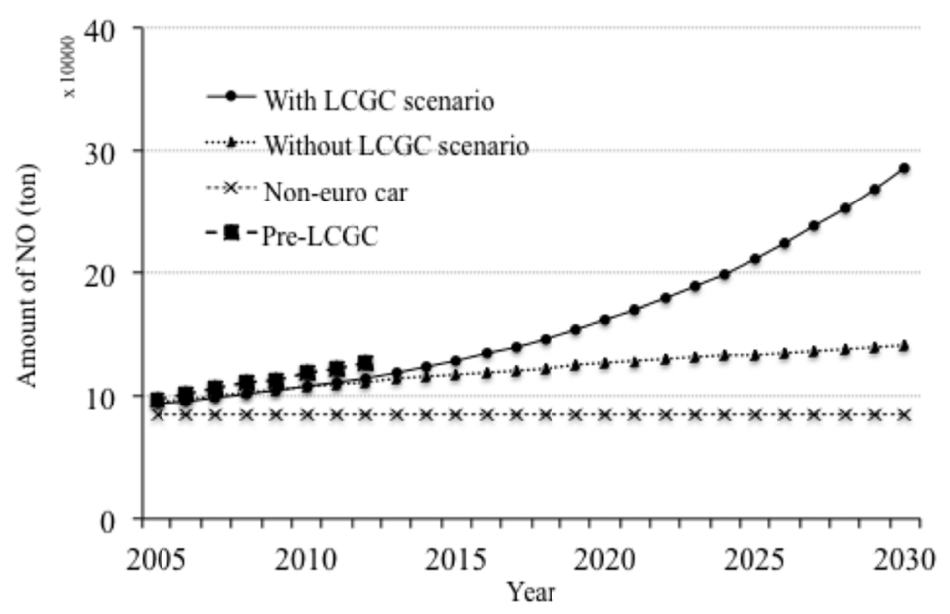

(c)

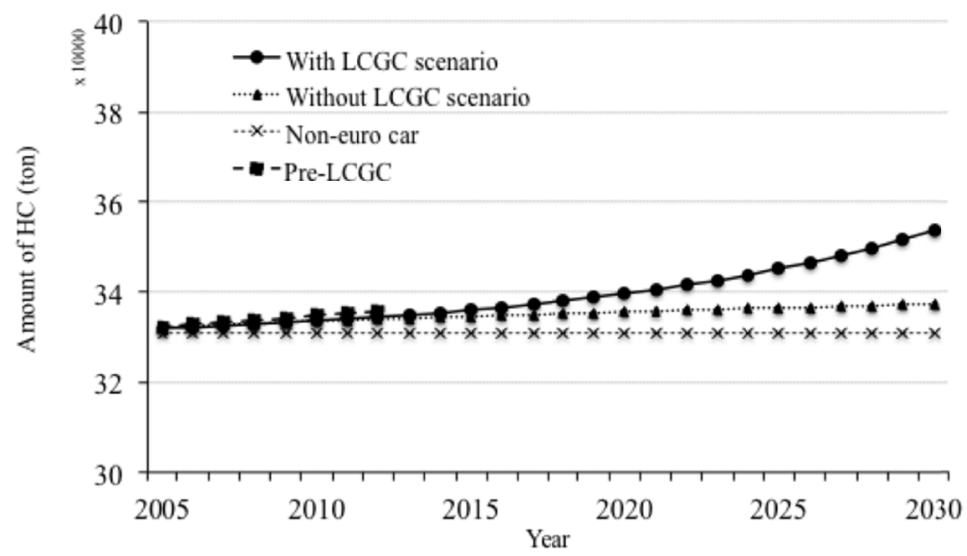

Figure 4. Previous and projected emissions of $\mathrm{CO}(\mathrm{a}), \mathrm{NO}(\mathrm{b})$, and $\mathrm{HC}(\mathrm{c})$

The gaps between emissions under the LCGC scenario and those under the scenario without LCGCs in each case are similar to the gap between the growth in the total number of cars with and without the LCGC policy shown in Figure 2. This confirms that the total number of cars is the most important factor in determining the overall level of emissions. As long as there is no change to the emissions control system in vehicles or to the emissions standard, all vehicles are assumed to produce emissions in accordance with the Euro 2 standard.

Stricter emissions regulations will force automotive manufacturers to improve the technology in their vehicles to meet the more stringent requirements. The effect of the LCGC policy on the environment is a crucial issue. Considering only some of the effects of a new policy, while overlooking other possible effects, means that the 
overall cost of policy implementation might exceed the expected benefits. Thus, a comprehensive analysis should be undertaken prior to policy implementation.

This analysis indicates that controlling the number of cars is an effective means of controlling emissions. One way to control the number of cars is to limit new car purchases. However, this contradicts other government aims, because increased vehicle sales signify economic growth, as well as a rise in people's standard of living. Hence, controlling the number of cars is not as easy as simply preventing people from buying a new car. Others solutions should be considered, such as controlling the number of older cars, which contribute more emissions because of the deterioration of their catalytic converters, and motivating people to accelerate their car replacement plans. Regulating the down payment that was required when purchasing a new vehicle was expected to control the rapid growth in the number of vehicles by ensuring that only buyers with sufficient annual income could obtain loans. However, the simultaneous implementation of the LCGC policy led to an increase in the number of cars by making it possible for more people to purchase a car.

\subsection{Estimation of $\mathrm{CO}_{2}$ Emissions, Validation, and Future Projections}

$\mathrm{CO}_{2}$ emissions from LCGCs $(G C A)$ and non-LCGCs $(G C B)$ were estimated using equation (8). $G C A$ and $G C B$ are influenced by $F C A$ and $F C B$. Since $F C A$ has been regulated under the LCGC policy, equation (6) is used to calculate an FCA of 650 liters with an $A T D$ of $13,000 \mathrm{~km}$. In relation to non-LCGCs, $F C B$, which was obtained from our survey of drivers, was 1,200 liters, which means fuel consumption of $9.8 \mathrm{~km} / \mathrm{L}$ using the same $A T D$, or nearly double that of LCGCs. A similar $A F C$ value for non-LCGCs of 1,210 liters per year has been used to estimate the potential fuel savings from introducing fuel economy labels for passenger cars in Indonesia (Silitonga et al. 2011) and to undertake a cost-benefit analysis in a follow-up study (Atabani, Silitonga, and Mahlia 2012). In the current study, $A F C$ of $20 \mathrm{~km} / \mathrm{L}$, which is obligatory for LCGCs, is considered to be an improvement brought about by the implementation of the LCGC policy. This gives an FCB value that is approximately 1.8 times better than that for current non-LCGCs. However, the large difference between the values for LCGCs and non-LCGCs $(550 \mathrm{~L} /$ year) leads to a significant difference between pre-LCGC figures and the estimated values. A failure to enforce the new down payment regulations has also contributed to a level of car ownership that does not reflect people's purchase ability based on their annual income.

Estimated $\mathrm{CO}_{2}$ emissions under the LCGC scenario show an increase until 2030, as shown in Figure 5. Large gaps between forecast emissions with and without the LCGC policy are predicted. The gradient of the curve is also rising, reflecting an acceleration of the increase in emissions under the LCGC policy compared to that without the LCGC policy. Although LCGCs have better fuel consumption than non-LCGCs, the growth in the number of LCGCs more than offsets the improvement in fuel consumption. Thus, total $\mathrm{CO}_{2}$ emissions will be higher, as shown in Figure 5.

By 2023, $\mathrm{CO}_{2}$ emissions under the LCGC scenario will be nearly 2.6 times greater than those under the scenario without LCGCs. The gap continues to increase until 2030, by which time it will be 3.3 times bigger, with 49,411 tons and 14,892 tons of $\mathrm{CO}_{2}$ being emitted with and without LCGCs, respectively. 


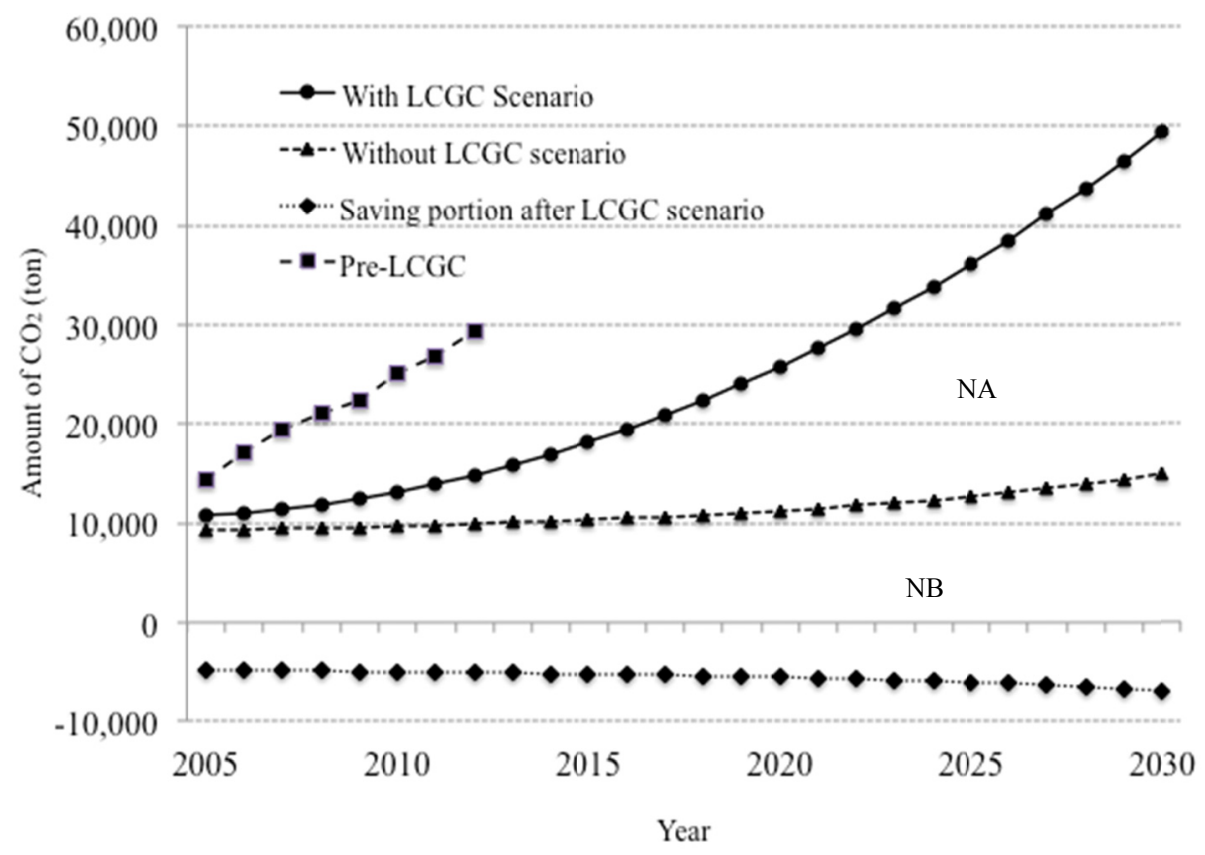

Figure 5. $\mathrm{CO}_{2}$ emissions with and without the implementation of the LCGC policy

The saving portion from LCGC policy is shown on minus portion as positive effect from LCGC policy, because it controls fuel consumption with minimum requirement. An individual car is able to save more than half fuel consumption and $\mathrm{CO}_{2}$ emission from engine combustion. Even though the LCGC scenario shows higher $\mathrm{CO}_{2}$ emissions than the scenario without LCGCs, it also contributes to a reduction in $\mathrm{CO}_{2}$ emissions. Between 2013 and 2030, $\mathrm{CO}_{2}$ emissions could be reduced by more than 104,881 tons. The growth of the new car from LCGC portion becomes much bigger compare to the individual car reduction. Cumulative $\mathrm{CO}_{2}$ emission form total new car population exceed saving from individual car improvement. Finally, the total $\mathrm{CO}_{2}$ gas emission is larger than the scenario without LCGC policy.

\subsection{Sensitivity Analysis}

We also conducted a sensitivity analysis to identify the significant factors contributing to the increase in emissions under both scenarios. We set sensitivity to $\pm 10 \%$ of the initial average car price and down payment, while loan duration was set to between three and eight years.

Increasing the price of the car and the down payment required and shortening the loan duration are all ways to reduce emissions. Conversely, reducing the car price and the down payment required and extending the loan duration will lead to increased emissions of $\mathrm{CO}, \mathrm{NO}, \mathrm{HC}$, and $\mathrm{CO}_{2}$ under both scenarios. Shortening the loan duration to three years has the greatest impact on emissions because this increases the minimum annual income requirement to US $\$ 8,307$ under the LCGC scenario and US\$14,165 under the scenario without LCGCs. This is predicted to reduce emissions by around $84.6 \%$ and $41.7 \%$ in the scenarios with and without the LCGC policy, respectively. However, this will also lead to a significant reduction in vehicle sales, and thus a detailed costbenefit analysis is required from an economic perspective.

Reducing the required down payment to $10 \%$ of the total car price also has a big impact under the LCGC policy scenario. A smaller down payment means that the minimum annual income required increases because purchasers have to pay higher monthly installments. A $10 \%$ down payment could reduce emissions by $42.4 \%$ from current levels under the LCGC scenario, while the reduction under the scenario without LCGCs is only $9.3 \%$. It is predicted that the original non-LCGC policy is already higher. Conversely, extending the loan duration to eight years provides the biggest reduction in emissions under the scenario without LCGCs. It will cause $A M$ is also decrease that make lower limit for annual income is also become wider. The improved fuel consumption of LCGCs $(20 \mathrm{~km} / \mathrm{L})$ cannot offset the growth in the total number of cars, as shown in Figure 5 , and thus total $\mathrm{CO}_{2}$ emissions are greater compared with the scenario without LCGCs. Figure 5 shows that the growth in the number of cars is a significant determinant of the gap in terms of emissions between the scenario 
with LCGCs and that without LCGCs. Other options available include adjustments to related factors such as increasing the car price and down payment and shortening the loan duration. However, the key determinant remains the growth in the number of cars.

Improvements in driving behavior can be achieved by educating people to drive effectively, with effective travel distance and minimum emission. Equipping vehicles with improved technology to reduce emissions, for example, those produced while vehicles are idling in traffic jams, is also an option.. The emissions standard could also be upgraded to Euro 3, Euro 4, or Euro 5, but this would require cleaner fuel with a lower sulfur content.

Table 3. Sensitivity analysis using average purchase price, down payment, and loan duration duration sensitivity analysis

\begin{tabular}{cccccc}
\hline & \multicolumn{2}{c}{ With LCGC scenario } & \multicolumn{2}{c}{ Without LCGC scenario } \\
\cline { 2 - 6 } Elements & $\begin{array}{c}\text { Set } \\
\text { value }\end{array}$ & $\begin{array}{c}\text { Minimum } \\
\text { annul income } \\
(\mathrm{AM})(\mathrm{USD})\end{array}$ & $\begin{array}{c}\text { Rate of change of } \\
\text { emission amoun } \\
\left(\mathrm{CO}, \mathrm{HC}, \mathrm{NO}, \mathrm{CO}_{2}\right) \\
(\%)\end{array}$ & $\begin{array}{c}\text { Minimum } \\
\text { annual income } \\
(\mathrm{AM})(\mathrm{USD})\end{array}$ & $\begin{array}{c}\text { Rate of change of } \\
\text { emission amount } \\
\left(\mathrm{CO}, \mathrm{HC}, \mathrm{NO}, \mathrm{CO}_{2}\right) \\
(\%)\end{array}$ \\
\hline $\begin{array}{c}\text { Average price } \\
\text { (USD) }\end{array}$ & $+10 \%$ & 5,482 & $-21.8 \%$ & 10,388 & $-3.9 \%$ \\
\hline $\begin{array}{c}\text { Downpayment } \\
\text { (DP) (USD) }\end{array}$ & $-10 \%$ & 4,486 & $0.3 \%$ & 8,499 & $15.0 \%$ \\
\hline \multirow{2}{*}{ Duration (N) } & $-10 \%$ & 3,560 & $-42.4 \%$ & 10,927 & $-9.3 \%$ \\
& 3 year & 8,307 & $-80.9 \%$ & 6,071 & $39.3 \%$ \\
\hline
\end{tabular}

\section{Conclusions}

The implementation of an LCGC policy will have a potentially significant impact on changes in the levels of emissions of CO, NO, and HC. By 2030, emissions under the LCGC scenario are predicted to be significantly higher than those under a scenario without LCGCs. Emissions of CO, NO, and HC under an LCGC scenario are estimated to be $1,389.7,31.0$, and 279.5 tons, respectively, while those under a scenario without LCGCs are estimated to be $670.3,15.1$, and 136.6 tons, respectively, increases of $51.7 \%, 48 \%$, and $51.2 \%$, respectively. $\mathrm{CO}_{2}$ emissions in 2030 under the LCGC scenario are estimated to be 3.3 times higher than those under the scenario without LCGCs. The improved fuel consumption of LCGCs is insufficient to offset the predicted rapid growth in purchases of LCGCs by people with an annual income of US\$4,500-\$10,000 who have been unable to purchase a car in the past.

Increasing the price of the car and the down payment required and shortening the loan duration are all ways to limit the growth in the number of vehicles. Conversely, reducing the car price and the down payment required and extending the loan duration will lead to an increase in emissions of $\mathrm{CO}, \mathrm{NO}, \mathrm{HC}$, and $\mathrm{CO}_{2}$ under both scenarios, i.e. with and without LCGCs. Considering more detail about non-euro car (old car) is one of remaining topic that should be studied in the future.

A comprehensive study of the LCGC policy is necessary to ensure that emissions are kept to a minimum. Controlling the growth in the number of cars is one way to limit increases in emissions. However, a balance needs to be achieved between stimulating economic growth and controlling the growth in the number of cars. Accelerating the retirement of older cars with higher emissions levels as a result of deterioration of their catalytic converter is one way to achieve this balance. The introduction of new technology to reduce emissions in certain driving situations (e.g., while idling during traffic jams) or to reduce overall emissions (e.g., hybrid car technology) is another area that requires further study.

\section{Acknowledgements}

This work was supported as a special project in the Tokai Laboratory, Osaka University. We would also like to thank the Society for Risk Analysis Asia for their support and advice during the International Conference in Taiwan on 21-23 August 2014. We would also like to thank our colleagues Dr. Kojima Naoya and Dr. Leticia Sarmento Dos Muchangos for their support and fruitful discussions that enabled us to complete this research. We thank Geoff Whyte, MBA, from Edanz Group (www.edanzediting.com/ac) for editing a draft of this manuscript. 


\section{References}

ADB. (2016). Asian Development Outlook 2016 Update: Meeting the Low-Carbon Growth Challenge.

Atabani, A. E., Silitonga, A. S., \& Mahlia, T. M. I. (2012). Cost Benefit Analysis and Environmental Impact of Fuel Economy Standards for Passenger Cars in Indonesia. Renewable and Sustainable Energy Reviews, 16(5), 3547-3558. https://doi.org/10.1016/j.rser.2012.01.001

BCA. (2016). Bank Central Asia. Suku Bunga Dasar Kredit (Prime Lending Rate) PT. Bank Central Asia, Tbk. Retrieved from https://www.bca.co.id/id/Individu/Sarana/Simulasi\%20Pinjaman/Simulasi-Kredit-KKB.

BI. (2013). Bank of Indonesia Regulation No. 15/40/DKMP about Minimum Downpayment for Housing and Otomotive Purchase. Retrieved

from http://www.bi.go.id/id/peraturan/perbankan/Documents/se_154014.pdf

BI. (2015). Bank of Indonesia, Suku Bunga Dasar Kredit (Prime Lending Rate). Retrieved from http://www.bi.go.id/id/perbankan/suku-bunga-dasar/Default.aspx.

Böckers, V., Heimeshoff, U., \& Müller, A. (2012). Pull-Forward Effects in the German Car Scrappage Scheme : A Time Series Approach, no. 56.

Borken-Kleefeld, J., \& Chen, Y. C. (2015). New Emission Deterioration Rates for Gasoline Cars - Results from $\begin{array}{llll}\text { Long-Term Measurements. } & \text { Atmospheric }\end{array}$ https://doi.org/10.1016/j.atmosenv.2014.11.013

Boulter, P. G. (2009). Emission Factors 2009: Report 6 - Deterioration Factors and Other Modelling Assumptions for Road Vehicles.

BPS. (2013). Central Bureau of Statistics Report 2013. Central Bureau of Statistics Report: Number of Domestically Assembled Motor Vehicles (Units), 2008-2013. Retrieved from https://www.bps.go.id/linkTabelStatis/view/id/1065.

BRI. (2016). Bank Rakyat Indonesia (People's Bank of Indonesia). Retrieved from http://promo.bri.co.id/main/product/main/kkb_bri

CDIAC. (2013). Carbon Dioxide Information Analysis Center (CDIAC) Report. Retrieved from http://cdiac.ornl.gov

EPA. (2014). US Environmental Protection Agency Annual Report.

Gaikindo. (2015). Automotive Car Association Report: Domestic Auto Market \& Exim by Category 2015. Retrieved from http://www.gaikindo.or.id.

GIDD. (2015). Global Income Distribution Database, Database Taken from UN National Bank (Purchased Data). Retrieved from https://www.canback.com/c-gidd/

Hennessy, H., \& Richard, S. J. T. (2011). The Impact of Government Policy on Private Car Ownership in Ireland. Economic and Social Review, 42(2), 135-157.

Hong Huo, et al. (2011). Modelling Vehicle Emissions in Different Types of CHinese Cities: Imprtance of Vehicle Fleet and Local Features. Environmental Pollution, 159, 2954-2960. https://doi.org/10.1016/j.envpol.2011.04.025

Hossain, A., \& Gargett, D. (2011). Road Vehicle-Kilometres Travelled Estimated from State / Territory Fuel Sales. Australasian Transport Research Forum, 1-15. Retrieved from http://www.atrf11.unisa.edu.au/Assets/Papers/ATRF11_0028_final.pdf.

Mandiri. (2016). Mandiri Bank, Suku Bunga Dasar Kredit (Prime Lending Rate). Retrieved from http://www.bankmandiri.co.id/article/mtf_kred_kons.aspx

MOE. (2003). Decree of the Minister of the Environment (MOE) of Republic Indonesia No. 141 Year 2003 Regarding New Type and Current Production Motor Vehicles Exhaust Emission Standard.

MOF. (2013). Ministry of Finance (MOF) Report. Retrieved from https://www.kemenkeu.go.id

MOI. (2013). Decree of The Ministry Of Industry (MOI) No.33/M-IND/PER/7/2013. Retrieved from https://www.google.co.jp/url?sa=t\&rct=j\&q=\&esrc=s\&source=web\&cd=1\&ved=0ahUKEwiFwpqhn7HYA hWFGpQKHUcxCzIQFggkMAA\&url=http\%3A\%2F\%2Fregulasi.kemenperin.go.id\%2Fsite\%2Fdownload _peraturan\%2F1512\&usg=AOvVaw1_8iRsuH4gp71Te0hSA4qb

Nugroho, S. B., \& Fujiwara, A. (2005). Evaluating the Effects of a New Vehicle Emission Standard on Urban Air 
Quality in Jakarta City. Journal of International Development and Cooperation, 11(2), 17-37.

Pongthanaisawan, J., \& Sorapipatana, C. (2010). Relationship between Level of Economic Development and Motorcycle and Car Ownerships and Their Impacts on Fuel Consumption and Greenhouse Gas Emission in Thailand. Renewable and Sustainable Energy Reviews, 14(9), $2966-2975$. https://doi.org/10.1016/j.rser.2010.07.034

Sanjaya, K. K., Indriani, D., \& Tantri, M. (2014). Customers Motivation to Purchase Low Cost Green Car in Indonesia. Journal of Business and Management, 3(6), 646-655.

Silitonga, A. S., Atabani, A. E., Mahlia, T. M. I., \& Sebayang, A. H. (2011). Techno-Economic Analysis and Environmental Impact of Fuel Economy Labels for Passenger Cars in Indonesia. Renewable and Sustainable Energy Reviews, 15(9), 5212-5217. https://doi.org/10.1016/j.rser.2011.03.033

TAM. (2013). Toyota Astra Motor, Toyota Car Price List. Retrieved from http:/www.toyota.astra.co.id/shopping-Tools/pricelist

Yamamoto, T., Madre, J. L., \& Kitamura, R. (2004). An Analysis of the Effects of French Vehicle Inspection Program and Grant for Scrappage on Household Vehicle Transaction. Transportation Research Part B: Methodological, 38(10), 905-926. https://doi.org/10.1016/j.trb.2004.02.001

\section{Appendix A}

Annual income data

\begin{tabular}{|c|c|c|c|c|c|c|c|c|c|c|}
\hline \multirow[b]{2}{*}{ Year } & \multicolumn{9}{|c|}{ Segmented annual income (USD) } & \\
\hline & $<350$ & $350-550$ & $550-800$ & $800-1,100$ & $1,100-1,600$ & $1,600-2,500$ & $2,500-4,500$ & $4500-10,000$ & $\begin{array}{l}10,000- \\
25,000\end{array}$ & \\
\hline 2001 & $61,563,297$ & $55,637,296$ & $37,991,127$ & $22,108,240$ & $15,453,941$ & $10,841,285$ & $6,298,447$ & $1,789,349$ & 273,433 & \multirow{15}{*}{ 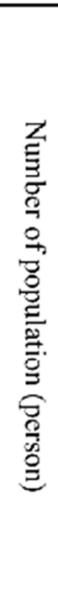 } \\
\hline 2002 & $59,280,830$ & $56,454,213$ & $39,280,328$ & $23,177,571$ & $16,497,223$ & $11,411,351$ & $6,713,565$ & $1,912,748$ & 295,479 & \\
\hline 2003 & $56,261,173$ & $57,792,129$ & $40,734,737$ & $24,426,667$ & $17,505,025$ & $11,971,057$ & $7,079,124$ & $2,044,644$ & 314,936 & \\
\hline 2004 & $51,762,955$ & $58,313,333$ & $43,852,995$ & $26,134,350$ & $18,665,590$ & $12,481,055$ & $7,477,405$ & $2,250,078$ & 337,763 & \\
\hline 2005 & $49,266,481$ & $58,339,116$ & $45,647,601$ & $27,622,177$ & $19,873,903$ & $13,125,414$ & $7,767,610$ & $2,459,172$ & 359,464 & \\
\hline 2006 & $47,277,486$ & $58,412,124$ & $47,486,858$ & $28,927,948$ & $20,899,609$ & $13,533,966$ & $8,143,882$ & $2,628,315$ & 378,257 & \\
\hline 2007 & $43,759,024$ & $57,727,670$ & $49,566,016$ & $30,684,968$ & $22,815,607$ & $14,324,131$ & $8,780,779$ & $2,880,755$ & 410,472 & \\
\hline 2008 & $39,854,424$ & $56,939,949$ & $51,043,453$ & $32,869,913$ & $24,996,576$ & $15,246,168$ & $9,584,503$ & $3,224,333$ & 456,589 & \\
\hline 2009 & $35,556,408$ & $56,371,225$ & $52,428,029$ & $35,238,908$ & $26,990,402$ & $16,473,660$ & $10,345,458$ & $3,550,136$ & 501,211 & \\
\hline 2010 & $32,783,380$ & $55,967,522$ & $53,316,700$ & $36,979,732$ & $28,546,563$ & $17,627,007$ & $11,041,230$ & $3,835,155$ & 543,914 & \\
\hline 2011 & $30,320,772$ & $55,024,516$ & $54,281,312$ & $38,531,998$ & $30,145,832$ & $18,905,756$ & $11,817,828$ & $4,140,082$ & 593,973 & \\
\hline 2012 & $27,773,853$ & $53,309,946$ & $55,298,125$ & $40,098,385$ & $32,030,550$ & $20,445,460$ & $12,701,055$ & $4,503,367$ & 658,029 & \\
\hline 2013 & $25,021,142$ & $50,644,698$ & $55,781,005$ & $42,059,085$ & $34,556,602$ & $22,241,477$ & $13,682,857$ & $5,082,474$ & 742,673 & \\
\hline 2014 & $22,751,578$ & $48,176,413$ & $55,873,943$ & $43,717,340$ & $36,962,870$ & $24,106,752$ & $14,656,700$ & $5,673,631$ & 830,615 & \\
\hline 2015 & $19,915,495$ & $45,888,741$ & $55,175,319$ & $45,230,126$ & $39,825,501$ & $26,531,285$ & $15,778,985$ & $6,351,079$ & 938,585 & \\
\hline
\end{tabular}

\section{Copyrights}

Copyright for this article is retained by the author(s), with first publication rights granted to the journal.

This is an open-access article distributed under the terms and conditions of the Creative Commons Attribution license (http://creativecommons.org/licenses/by/4.0/). 